through the mass, the common bile duct, the hepatic artery, and the portal vein were divided, their mouths being quite patulous and their calibre undiminished."2 The tissue here possessing no marked contractile property, the vessels, though embedded in the same, did not suffer. At a further stage of the growth, of course, compression would ensue, with narrowing or occlusion of one or more vesselo, according to the resistance they might respectively offer. But then the modus operandi would be that of a pretty uniform constriction, comparable to the slow tightening of a ligature. Not so, however, in the class of case dealt with in this paper. We use the terms contraction and constriction in discussing the same, but, as has been pointed out, the contraction of cicatricial tissue in cases of this kind is, strictly speaking, a concentric retraction, a shrinking which takes place in all dimensions, and is directed in radial lines towards a centre or centres which are determined by the cunditions of the original lesion, and the foci, one or more as the case may be, of tissue destruction. Hence the effect on vessels, ducts, \&c.; traversing the area of cicatrisation, is rather an irregular traction or torsion than a uniform constriction as in the former instance. And hence also it happens, that in the same cicatricial area, while one vessel is implicated, another is not at all so, or only in a minor degree. Bath.

\section{THE RELIEF OF THE MORPHIA CRAVING BY SPARTEINE AND NITRO-GLYCERINE. ${ }^{3}$}

BY OSCAR JENNINGS, M.D., M.R.C.S., ELECTRIGAL PHYSICIAN TO THE CLINIQUE OF ST. ANNE.

IN a note on the Condition of the Pulse in Morphinomanis presented by Professor Ball and myself at the French Academy of Sciences, ${ }^{4}$ we discussed the mechanism of the morphis craving, and showed that during the period of privation there is ischæmia of the general circulation. An injection of morphia administered at this time causes a disappearance of the psycho-somatic suffering which constitutes the craving, and is followed by a restoration of the pulse. In a second communication to the Academy of Medicine ${ }^{5}$ we stated that we had found, moreover, that the morphia craving can be appeased by the use of other medicines having the property of restoring the pulse in a similar manner. We had experimented extensively with two agents of the kind on patients at Laennec, St. Anne, and in our private practice. The first of these is sparteine. "We thought it would be preferable to try heart tonics, and strengthen the action of this organ in moments of weakness. To this end we have employed sulphate of sparteine, which fulfils most of the conditions, and can easily be administered by hypodermic injections. We watch for the moment of weakness as indicated both by plateau in the sphygmographic tracings and by the intimate sensations of the patient. At this moment we administer an injection of from two to four centigrammes, which may be repeated when necessary, and at the expiration of a few minutes we see the pulse strengthen and the craving disappear. To use the words of one of our patients, 'the medicine gives heart.' This expresses in familiar language a physiological truth of which the sphygmograph confirms the absolute exactitude ...... Another medicine which procures a passing relief of the symptoms is nitro-glycerine. Its effects, very similar to those of sparteine as regards the point in question, are at the same time much more rapid and much more ephemeral."

Since the preceding lines were written $I$ have administered sparteine and nitro-glycerine repeatedly in fourteen different cases, and I feel convinced that in these agents, properly administered, we possess a means which will enable - any morphia habitué earnestly desirous of leaving off his intemperance to carry the process of weaning to a successful issue. All morphia habitués have from time to time a maudling hysterical desire to give up the practice, but this vanishes at the tirst feeling of discomfort. For such cases there can be no suppression without restraint, and a result

Fxtract from the post-mortem notes.

3 Read at the Sociêtê Médicale de l'mlysêe of Paris.

4 Des Modifications da Pouls dans la Morphinomanie. Comptes Rendus de l'Académie des Sciences. March, 1887.

Considerations sur le Traitement de la Morphinomanie. Bulletin de l'Académie de Médicine. March, 1887. so obtained is very unsafe for the future. Deprived of their morphia in an asylum, patients are not thereby cured of the craving. They have been forced by a compulsion, which bas provivionally taken the place of their will, and a morphinomaniac is no more cured of his passion by this forced deprivation than is the dipsomaniac by abstinence from alcohol during a certain time. A relapse generally occurs as soon as the patient has recovered his liberty. But there are morphia habitués who honestly loathe their thraldom, and who would do anything short of the impossible to break through it. Very few medical men seem to realise the nature and intensity of the euffering which accompanies the privation from morphia, and upon which they are occasionally called upon to advise. A gentleman, whose case I related in the Encéphale of Marcb, 1887, and who was cured of the habit by inhibition of the craving, was informed by some of the consultants he had seen that the confirmed babit of morphia was incurable. I believe it is the writer of the section on Morphinism in Ziemssen's Cyclopædia who is responsible for this opinion. But the greater number of his previous advisers liad been of opinion that all that was necessary to cure him of the habit was for him to "throw away his syringe and solution, and just make up his mind not to get any more."

Now, the truth lies between these extremes of theoretical error and practical ignorance. Some morphia habitués would have sufficient resolution to wean themselves of the practice of the terrible distress resulting from privation if this could be alleviated in a certain measure; and it is to these that I refer when I say that those who are earnestly desirous of breaking off the habit can be enabled to do so by the help of sparteine and nitro-glycerine. To be properly administered the remedies mentioned must only be used when really needed, and should not therefore be at the patient's disposa]. The only results I have ever seen of giving succedanea to morphinomaniacs has been to complicate the first disease by a second, and very often a much more dangerous, intemperance. And just as I have seen morphia habitués acquire an additional craving for alcohol, chloral, cocaine, and other drugs of the kind, so I think it quite possible that the reckless and uncontrolled administration of the medicines I recommend may give rise to an artificial desire for them-a possibility foreshadowed by Dr. Murrell in his work on Nitro-Glycerine in Angina Pectoris. Given at the right moment, and in suitable doses, spartsine and nitro-glycerine, either separately or together, form an admirable means of relieving the morphia craving, and the only modification I have to make in the statement quoted above is with reference to the intensity and duration of the action of nitro-glycerine. Further, experience has taught $m \theta$ that the effect of nitro-glycerine is most satisfactory and persistent in those cases where there is a predominance of the "yearning" over the "craving" - that is to say, in which the psychical symptoms are more distressing than those of a somatic order. When, on the other hand, there is more physical craving than morphine-nostalgia, as I have termed it, the use of sparteine, which is a tonic to the circulation, gives better results than nitro-glycerine alone, which I take to be nervo-inhibitory. What, however, I would especially insist upon in the present note, is that, in the simultaneous administration of the two drugs, the one by subcutaneous injection and the other placed upon the tongue, we possess a perfect remedy for the morphia craving in its double psycho-somatic modality. Some patients, as would naturally be expected, say that one or both drugs fail to give them relief; but, as far as my experience goes, these are persons who have no real intention of giving up their morphia. Indeed, all they desire is to be allowed to indulge without interference in their vice. But those who have retained sufficient will to resist the first promptings of a capricious impulse will find that the true morphia bunger can be entirely appeased by sparteine and nitro-glycerine. taken when there is a genuine necessity. The subjoined sphygmographic tracings show better than a lengthened description the relative values of the two remedies.

Tracings Nos. 1 and 2 were taken from a patient at Laennec, whose case is partially reported in my little work on Morphinomania ${ }^{6}$ No 1 being before, and No. 2 after, an injection of morphine; the first shows the state of craving, the second that of satisfaction. No. 3 is a tracing of the same pulse after a hypodermic injection of sparteine instead of morphine. The patient having stated that the sparteine 


\section{SPHYGMOGRAMS ILLUSTRATING THE CASES.}

N'1

$r+\sqrt{n}+\sqrt{n} \sqrt{m}$
NO8

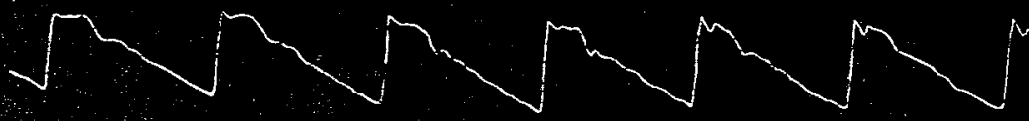

№ 9

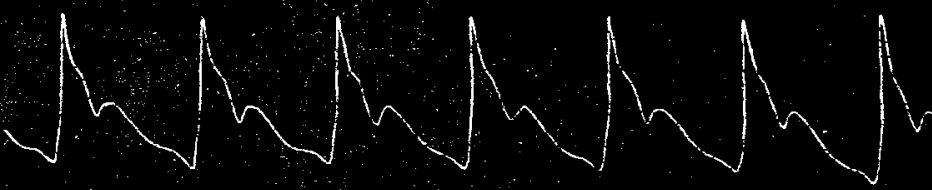

№ 10

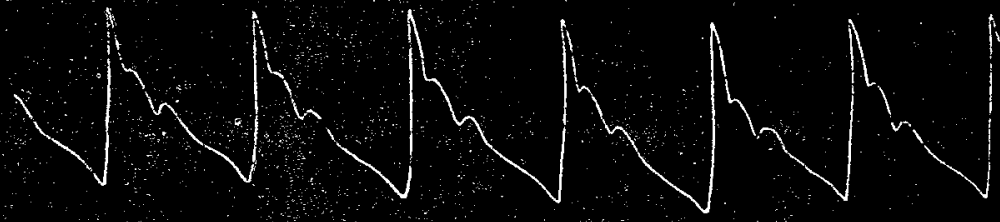

No 5

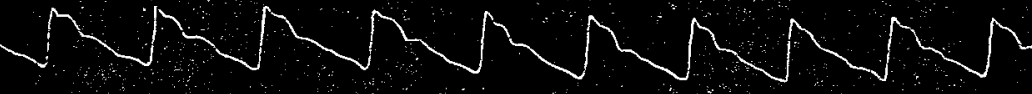

N:6

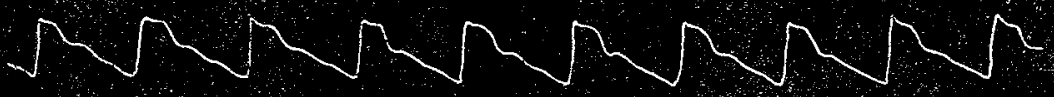

NNo 4

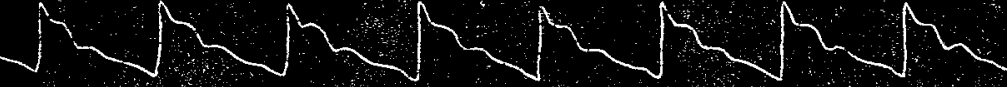

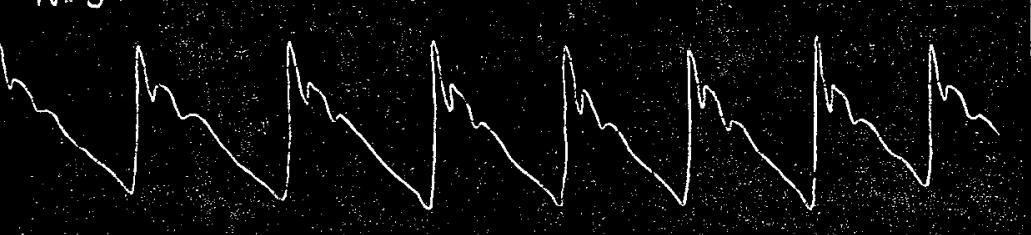


"gave her heart," the morphia was suppressed, and she was given two grains per day ot sparteine instead of half a grain of morphia, to which she had decreased from eight grains, to which she had been accustomed for seven years. Thanks to the sparteine and occasional faradisation, she got over the craving in three weeks.

Nos. 4, 5, and 6 are the sphygmograms corresponding to different degrees of morphia hunger in a young medical man, who had taken morphia for insomnia six years previously, and had become accustomed to twelve grains per day. The whole suppression took less than a month, and fifteen days after the last injection of morphia his pulse kept up by nitro-glycerine was as in No. 7. A few days Jater he was entirely cured, and took no substitute whatever. In a letter to me on the effect of the different medicines employed, he says: "Antipyrin congested the brain the first time. At the third or fourth trial it produced no further effect. Its action diminished progressively. As to any relief it procured, it was very trifling. What did procure me the greatest relief, and which replaced by its effects the morphia, was without doubt nitro-glycerine. In a state of craving, at the time of my worst sufferings two or three drops, taken every three or four hours sufficed to remove all agitation and restlessness, and perhaps also perspiration. I will not be positive about this last point, as I only remarked it once. As regards the nitro-glycerine, its action increased progressively. I tried the tablets of nitroglycerine, which had the same effect as the solution, and at the present moment it suffices for me to take a single tablet to congest the brain, and so procure a mild and pleasant intoxication resembling that of morphia."

The next three tracings relate to a woman whose pulse during her cure at St. Anne presented the truncated appearance which constitutes the plateau of morphia craving. The administration of sparteine had enabled her to be weaned of morphia without difficulty. Six weeks after the cessation of the treatment I took her pulse with a view to ascertain whether her habit, which was of ten years' duration, had left any permanent injury to the vascular tonicity. The tracing No. 8 indicated that the circulation was unsatisfactory, and with very little persuasion the patient told me that she felt uncomfortable about the heart, and would certainly be obliged to resort to morphia when she recovered her liberty unless she could brace herself up by sparteine. I suggested that she should try nitro-glycerine instead, and placed successively four drops of the 1 per cent. solution on her tongue. Five minutes afterwards she said she felt much more comfortable, and the pulse showed an improvement as in No. 9. She still maintained, however, that something more was needed to keep her away from morphia, so I injected two centigrammes of sparteine, with the effect seen in tracing No. 10, the patient expressing herself perfectly satisfied.

The last three sphygmograms form an interesting contrast to the three preceding. The pulse tracing on the day before having been found by the clinical clerk to present my plateau, Professor Ball had ordered sparteine. The pulse at 10.30 was as in No. 11 ; but notwithstanding the satisfactory condition of the circulation, the patient was in a state of restlessness and enervation, unable to keep still, and crying hysterically. I gave her two drops of nitro-glycerine solution. The effect upon the circulation was greater than in any case I have seen; but although the hyperdicrotism made me feel a little uneasy, the patient was thoroughly comfortable and became quite cheerful. I remained with her an hour and a half, during which time she was calm and tranquil, and before leaving took a tracing, which showed that the arterial tension was entirely restored. (See No. 13.)

The last two cases are extremely instructive. The patient whose symptoms were associated with a condition of the circulation shown in Fig. 8 has a bodily malaise depending partly on an embarrassed action of the heart. Her urine contains albumen. Here the nitro-glycerine was insufficient, and it was not until the condition of the heart was modified by sparteine to that shown in Fig. 10 that she expressed herself relieved. The woman whose pulse is recorded in Fig. 11, on the other hand, was not, as far as physical investigation could discover, suffering from the effects of ischæmia, and yet her distress was painful to witness. Here the successful remedy was nitro-glycerine.

To sum up, the morphia craving is a complex suffering, at the same time cerebral and peripheral, each factor of which can be relieved by appropriate treatment. The organic distress may be soothed by sparteine, which recovers the same way as a hypodermic injection of morphia. The cerebral craving (or yearning), often the more painful of the two, corresponds to a want of habitual congestion. This can be arrested by nitro-glycerine, which gives rise to the same kind of sensation in the morphia habitue deprived of his stimulant as the hypodermic injec. tion. It acts probably by inhibition a distance rather than by essential sedation of the nervous centres.

Paris.

\section{CORKAGE OF THE URETER WITH CLOT IN CASES OF ADVANCED CANCER} OF THE KIDNEY.

BY E. HURRY FENWICK, F.R.C.S.,

ASGISTANT-GTRGEOY TO THE LONDON HOSPITAL, SURGEON AND PATHOLOGIST TO ST. PETER'S HOSPITAX FOR URINARY DISEASH.

I HAVE long been strongly impressed with the necessity for adopting some measure, other than excision, in the treatment of cancer of the kidney. The statistics of nephrectomy show the futility of removing a kidney thoroughly attacked by carcinoma. Cases such as these are often met with in practice, but sometimes there is superadded a profuse and ungovernable hæmaturia- $\mathrm{a}$ hæmaturia which prostrates our patient, defies our remedies, and which slowly, always surely, reduces that short term of life allowed by the disease to a minimum. In casting about for some conservative measure to arrest the hæmorrhage, without attempting to remove its source, I bethought me of the skilful manner in which the ureter is sometimes spontaneously plugged with clot, obstructed by growth, or pressed upon and rendered impassable by the enlarged lower segment of the kidney; the hæmorrhage being thereby suddenly and permanently arrested. Post-mortem examination of these cases shows the pelvis to be distended with a large firm blood clot, and the canal to be impervious. It seemed to me to be within the range of possibility to imitate this, by inducing clottage of the blood in the ureteral canal, and it did not seem beyond the range of probability that the mere pressure of the distended pelvis upon the renal vessels would restrain slightly the flow of nourishment to the neoplastic growth, and thus reduce its rate of increase. The course I proposed to myself to adopt in a suitable case was to introduce into the bladder some form of instrument which would allow of the vesical orifice of the ureter being nipped between it and the compressing finger in the rectum. The instrument I decided upon was my ureter aspirator, ${ }^{2}$ which can be made to embrace either ureteral orifice without trouble. Although a good many cases of hæmaturia pass through my hands every year, yet it was not until 1885 that a case came under my care at St. Peter's Hospital which seemed to justify such an attempt being made. I submit this case not for criticism, for I regret to say it is incomplete; although its clinical aspect is strongly in favour of the conclusions I have drawn being correct, yet its pathological history is wanting, and without post-mortem evidence its accuracy is questionable and its value greatly diminished.

J. L- aged fifty-three, had been healthy up to July, 1881. On the 31 st of that month he received a severe blow upon his chest which caused him an hour afterwards to pass much blood in his urine. From that time he continued passing blood in large quantities and at irregular intervals for thirteen months. The hæmaturia was often apparently causeless in its origin, always painless in its course, and generally beyond the control of drugs. It used to stop gradually, only to reappear suddenly in a fow days' time. Thirteen months af́ter its onset he applied for relief at the out-patient department of St. Peter's Hospital, bringing with him a bottle of scarlet hæmaturia. He was at that time suffering from some pain in the right kidney, and had lately lost flesh and strength. He was very anæmic. There was no renal tumour to be felt, although pain was experienced on pressure in the region of the right kidney. No vesical or prostatic cause for the hæmorrhage was found. I explained the case to him, and, finding the hæmaturia unaffected by drugs, I advised attempting to close the right ureter with a clot, and failing

1 Abstract of a paper read before the Medical Society. 2 Vide The LaNcet, September 18th, 1886, p. 529. 